\title{
РАЗВИТИЕ ИНСТРУМЕНТОВ ПОДДЕРЖКИ МАЛОГО И СРЕДНЕГО ПРЕДПРИНИМАТЕЛЬСТВА В РФ
}

\author{
(C) 2021 Ял-Яваш (Ялымов) Сергей Вячеславович \\ Высшая инженерно-экономическая школа ИПМЭиТ \\ Санкт-Петербургский политехнический университет Петра Великого, Россия, Санкт-Петербург
}

Особенности развития сектора МСП указывают на несовершенство существующей системы государственной поддержки, требующей обновления аналитических инструментов для принятия управленческих решений. В условиях ресурсных ограничений и недостаточной динамики экономического роста, государство должно балансировать между поддержкой крупного бизнеса и поддержкой сектора МСП, и, как следствие, между общеэкономическими интересами государства и социальными потребностями населения. Поэтому подход к развитию поддержки сектора МСП должен быть основан на анализе системной трансформации институциональной среды и своевременной реакции МСП на следствия данной трансформации. Для решения данной задачи был проведен опрос предпринимателей, выявлены ключевые проблемы с точки зрения респондентов. На основании чего было предложено развитие инструментов государственной поддержки сектора МСП, что позволяет снизить волатильность внешней среды и повысить возможности предпринимателя по контролю за основными бизнес-процессами организации.

Ключевые слова: сектор малого и среднего предпринимательства, инструменты государственной поддержки, экспертный опрос, метод Дельфи, опцион на объём продаж

Средняя рентабельность субъектов МСП составляет 5,76\% [1], что нельзя назвать высоким результатом. Характерными причинами в данном случае являются низкая покупательная способность населения, совокупное высокое налоговое бремя (в частности, высокий уровень НДС) и недостаточный уровень государственной поддержки. Так как субъекты МСП работают, прежде всего, с физическими лицами, уровень благосостояния населения напрямую влияет на финансовые результаты субъектов МСП. Следствием данного факта являются дополнительные сложности для субъектов МСП не только в долгосрочном, но и среднесрочном планировании. Это ведёт к высокой чувствительности к большинству неблагоприятных явлений внешней экономической среды. Субъекты МСП вынуждены существовать за счет малой операционной прибыли, зачастую не имеют накоплений и средств для инвестирования в собственное развитие, что значительно повышает волатильность данного сектора экономики.

Описанная специфика развития сектора МСП указывает на несовершенство существующей системы государственной поддержки, а также общую поляризацию экономики с явным уклонов в сторону развития крупного бизнеса. Таким образом, принадлежность предприятия к сектору МСП во много может указывать на значительные риски планирования, следствием чего в условиях макроэкономической нестабильности и ресурсных ограничений может быть общеотраслевая нестабильность.

В рамках государственной политики применяются различные инструменты по поддержке развития малого и среднего предпринимательства. Одно из важных мест занимает льготное налогообложение, которое реализуется в рамках стимулирующей функции налогов. Это позволяет отдельным налогоплательщикам уплачивать налоги в меньшем объёме [2], что даёт возможность уменьшить денежные оттоки предприятия, а также формирует более благоприятные условия для ведения бизнеса.

Для развития и совершенствования поддержки предприятий малого и среднего предпринимательства в России, стоит обратить внимание на опыт других стран. Работа «Инвестиции и финансирование МСП с учетом взаимодействия банковской и налоговой систем, а так же за счет развития партнерства государственного и частного секторов экономики», авторами которой выступили исследователи из Китая - Пенгфей Луо, Дандан Сонг, Биао Чен, посвящена изучению возможностей развития малого и среднего предпринимательства за счет государственных 
субсидий и взаимодействия банковской и налоговой систем в Китае [3].

Так, в работе авторы уделили внимание развитию партнерских отношений между бизнесом и государством в КНР. Предложили инвестиционные стратегии и рассчитали размер предполагаемых потерь при выстраивании партнерских отношений с государственными органами власти. По мнению авторов исследования использование взаимозависимости банковской и налоговой систем экономики, представляет собой так называемый инструмент развития МСП, который может смягчить проблему недостаточного инвестирования средств в условиях рыночной нестабильности. Кроме того, была выявлена зависимость структуры кредитования МСП от размера налоговой ставки, распределения инвестиционных затрат, кредитного мультипликатора и волатильности. Данная работа показала всю сложность развития МСП в условиях постоянно меняющихся факторов внешней среды. Колебание даже одного из них приводит не только к прямым изменениям, но и к изменениям реакции субъектов МСП на изменение иных факторов.

В работе [4] рассматривается взаимосвязь между инновациями на уровне фирм и внешним финансированием МСП. Для проведения исследования была использована выборка из 13430 фирм из стран Восточной Европы и Центральной Азии. По мнению авторов, исследование имеет несколько важных политических последствий. Во-первых, важно иметь более широкую формализованную финансовую систему, которая способна заботиться о предпринимателях и различных стадиях жизненного цикла малых компаний.

В статье [5] рассмотрена проблема ограниченности доступа МСП к финансированию. Поэтому меры по содействию доступу МСП к финансовым ресурсам, а также содействие формированию условий их более эффективного расходования являются неотъемлемой частью стратегии развития многих правительств. В работе [6] исследована общая развитость МСП в России с точки зрения устойчивости экономической среды в зависимости от экономических циклов.

В рамках проводимого исследования был проведен опрос среди предпринимателей сектора общественного питания в г. Санкт-Петербург. Респондентами выступили совладельцы, руководители и экономисты субъектов МСП в коли- честве 53 человек. Получение экспертных оценок осуществлялось на основе метода Дельфи (как показано в работе [7]). Во время первого тура опроса респонденты были ознакомлены с исследованиями автора, с предлагаемой анкетой, включающей список актуальных проблем в предпринимательстве города. Также было предложено по необходимости уточнить данный список, расширить его. По итогам первого тура была выполнена корректировка представленного материала, из которого также были исключены дублирующие по содержанию пункты, составлена единая анкета.

Второй тур был обусловлен необходимостью для респондентов оценить в диапазоне баллов от 1 до 10 приоритеты по решению проблем предпринимателей в секторе общественного питания г. Санкт-Петербурга. По результатам второго тура мнения $57 \%$ респондентов в целом оказались совпадающими. Оценки 31\% опрошенных показали расхождение в среднем на $25 \%$. Остальные представили предпринимательского сообщества дали противоположные мнения о приоритетности решаемых проблем, и в т.ч. привели развернутые обоснования такого выбора.

Согласно методу Дельфи, в составе третьего тура все полученные ранее данные были доведены до мнения респондентов. Была поставлена задача проанализировать мнения коллег, и, при необходимости, уточнить содержание своей анкеты. Часть респондентов скорректировали свое мнение. Общая доля согласованных анкет после это составила 67\%. Таким образом, список актуальных к решению проблем в предпринимательстве сектора общественного питания г. Санкт-Петербурга выглядит следующим образом (список ранжирован по приоритетности в соответствие с проведённым опросом):

1. изменчивость экономической среды на макро- и мезоуровнях;

2. налогообложение выше приемлемого уровня;

3. снижение спроса в результате пандемии;

4. высокие процентные ставки по заёмным финансовым ресурсам;

5. волатильность национальной валюты по отношению к доллару США и евро;

6. проблемы получения долгосрочных кредитных ресурсов;

7. высокие постоянные издержки; 
8. институциональные барьеры (законодательство и правоприменительная практика, бюрократия);

9. сложности привлечения квалифицированных кадров;

10. конкуренция с импортом.

Как можно отметить, респонденты на первые места поставили волатильность экономической среды на макро- и мезоуровнях, а также общие проблемы с повышенным налогообложением. При этом проблемы, связанные с конкуренция вообще оказались на последнем месте.

Для снижения волатильности следует задействовать элементы хеджирования с помощью производных финансовых инструментов. И, если для уменьшения валютных рисков можно использовать торгуемые на Московской бирже фьючерсные контракты и биржевые опционы, а также форвардные контракты, позволяющие зафиксировать валютный курс по будущей сделке (доступные через многие коммерческие банки), то изменчивость других факторов невозможно захеджировать на приемлемом уровне имеющимися биржевыми инструментами.

Поэтому так важно расширять инструменты поддержки малого и среднего предпринимательства в РФ, в основе которых будет положен принцип опционного контракта. Это позволит снизить волатильность внешней среды для предпринимателя и сосредоточиться на основных бизнес-процессах компании.

В работах $[8,9]$ предложены инструменты, основанные на принципе опционного контракта. Такие как опцион на налоговые обязательства субъекта МСП и опцион на финансовую устойчивость МСП. В первом случае базисным активом выступает прогнозируемый оборот субъекта МСП, во втором случае - финансовое состояние субъекта МСП как произведение уровня финансовой устойчивости на затраты на осуществление инвестиционного проекта.

В статье [10] выделены современные финансовые и имущественные инструменты поддержки субъектов малого и среднего предпринимательства, которые реализуются в составе государственной политики на региональном уровне:

- льготное налогообложение;

- субсидирование процентных ставок по банковским кредитам и лизингу;

- субсидирование затрат в рамках совместного финансирования инвестиционных проек- тов предпринимателя;

- государственные и муниципальные гарантии предпринимателям;

- грантовая поддержка;

- предоставление в аренду офисных помещений для предпринимательской деятельности;

- предоставление в аренду производственных помещений для предпринимательской деятельности;

- сдача в аренду земельных участков на льготных условиях.

Для снижения волатильности макро- и мезосреды, в условиях которых осуществляют свою деятельность предприниматели, возможно заложить принцип опционного контракта в основу каждого инструмента.

Например, реализацию предоставления помещений и земельных участков можно осуществлять в двух вариантах: по традиционной схеме и с использованием опционного контракта. В качестве базового актива может выступать коэффициент реализации объёма продаж субъекта МСП.

А именно:

$$
\begin{aligned}
& C=P * E \\
& K=\frac{P C_{p}}{P C_{n}} \\
& E=S * e^{-r_{f} * T * N}\left(\frac{\ln \frac{R}{S}+\left(r_{f}+\frac{\sigma^{2}}{2}\right) * T}{\sigma \sqrt{T}}\right)
\end{aligned}
$$

Где:

1. С - цена опциона;

2. $\mathrm{P}$ - коэффициент реализации объёма продаж субъекта МСП;

3. $\mathrm{PC}_{\mathrm{p}}-$ текущий уровень выручки субъекта МСП;

4. $\mathrm{PC}_{\mathrm{n}}-$ нормативный уровень выручки субъекта МСП;

5. Е - затраты на аренду;

6. S-размер арендной платы;

7. $\mathrm{R}$ - приведенная стоимость денежных потоков от аренды, которую компания получит в результате деятельности субъекта МСП;

8. Т- срок аренды;

9. $\mathrm{r}_{\mathrm{f}}$ - годовая безрисковая процентная ставка (скорректированная в соответствии с отраслевой спецификой);

10. $\sigma-$ уровень риска реализации проекта 
(определяется экспертным методом);

11. $\mathrm{N}(\mathrm{d})$ - кумулятивное стандартное нормальное распределение вероятностей.

Показатели С и Е измеряются в денежных единицах. Показатель Р составляет долю от нормативного значения. Таким образом, организация, которая приобрела данный опцион, получает право на инвестиционный доход в случае увеличения цены базисного актива. В свою очередь, повышение цены базового актива зависит от роста выручки малого или среднего предприятия. Т.е., субъект МСП получает дополнительную защиту в случае неблагоприятного стечения обстоятельств, эквивалентную снижению арендной платы при уменьшении выручки от продаж, а арендодатель сможет претендовать на потенциальный инвестиционный доход при выполнении плана роста предприятия.

Таким образом, предлагаемые инструменты развивают спектр возможностей предпринимателей в условиях возросшей волатильности внешних условий, а также позволяют принимать более взвешенные управленческие решения [11]. Их реализация возможна во многих отраслях, где присутствуют субъекты МСП, а получение выручки нестабильно [12].

\section{Библиографический список}

1. Малое и среднее предпринимательство в России.- Текст: электронный // Федеральная служба государственной статистики: [сайт]. - URL: https://gks.ru/folder/210/document/13223.

2. Кучеренко, О.В. Особенности налогового регулирования малого и среднего предпринимательства в России и за рубежом // Наука о человеке: гуманитарные исследования. - 2015. - С. 184-193.

3. Luo Pengfei, Song Dandan, Chen Biao Investment and financing for SMEs with bank-tax interaction and publicprivate partnerships // International Review of Economics \& Finance, 2020, vol. 65, issue C, 163-172

4. Nirosha Hewa Wellalagea, Viviana Fernandez Innovation and SME finance: Evidence from developing countries // International Review of Financial Analysis. 2019. https://doi.org/10.1016/j.irfa.2019.06.009

5. Renate Kersten, Job Harms, Kellie Liket, Karen Maas Small Firms, large Impact? A systematic review of the SME Finance Literature // World Development, 2017, vol. 97, issue C, 330-348

6. Жолболдуева Д.Ш., Аширалиева Б. А. Малый и средний бизнес в развитых странах // Известия вузов Кыргызстана, № 6, 2015.

7. Сулин М.А., Зайцев А.А. Концептуальные подходы к определению приоритетов государственного регулирования в аграрной сфере региона // Известия Международной академии аграрного образования.- СПб: Издательство МААО, 2015.- Вып. 21.- С. 120-125.

8. Родионов Д. Г., Ялымов С. В., Сергеев Д. А. Фискальный инструмент управления развитием сектора малого и среднего предпринимательства //Экономические науки. - 2020. - № . 189.- С. 92-98

9. Родионов Д. Г., Ялымов С. В., Конников Е. А. Модель институциональной среды субъектов малого и среднего предпринимательства //Экономические науки. - 2020. - № . 190.- С. 138-146.

10. Нестеренко И. Ю. Направления и инструменты поддержки предпринимательства на региональном уровне. // Стратегия развития регионов. - 2013.- № 31.- С. 12-21.

11. Стецюнич Ю.Н., Зайцев А.А.Информационные технологии в сфере налогообложения // Цифровая трансформация экономики и промышленности. Сборник трудов научно-практической конференции с зарубежным участием, 2019. С. 646-655.

12. Зайщев, А.А. Государственная поддержка аграрного производства РФ в условиях экономических санкций / А.А. Зайцев // Проблемы и пути социально-экономического развития: город, регион, страна, мир V Международная научно-практическая конференция.-СПб: Ленинградский государственный университет им. А. С. Пушкина (Санкт-Петербург), 2015.- С. 112-119. 